\title{
PENGUKURAN GREENSHIP EXISTING BUILDING VERSION 1.1 PADA BANGUNAN RUMAH REMPAH KARYA
}

\section{Ali Syarif Mustofa \\ Program Studi Arsitektur Fakultas Teknik Universitas Muhammadiyah Surakarta e-mail: alisyarifm@gmail.com}

\section{Qomarun}

Program Studi Arsitektur Fakultas Teknik Universitas Muhammadiyah Surakarta e-mail: qomarun@ums.ac.id

\begin{abstract}
ABSTRAK
Pemanasan global saat ini menjadi semakin parah dan memberikan dampak negatif terhadap bumi dan komponen di dalamnya. Perubahan kebiasaan manusia ternyata mampu mempengaruhi keberlangsungan kondisi bumi ini. Hal ini terbukti dengan perubahan gaya hidup yang ramah lingkungan membuat sistem kerja lingkungan membaik. Salah satu upaya dalam arsitektur guna menekan pemanasan global adalah dengan menerapkan sistem bangunan hijau pada suatu bangunan. Salah satu bangunan yang sedang berusaha untuk menerapkan sistem tersebut adalah Rumah Rempah Karya di Solo. Semula bangunan ini adalah gudang tempat penyimpanan material sisa-sisa proyek, lalu mengalami penambahan fungsi menjadi bangunan workshop material dan kantor dengan menggunakan material sisa dari proyek. Rumah Rempah Karya telah diklaim sebagai bangunan hijau, akan tetapi belum ada pembuktian dari klaim tersebut dan belum diketahui sejauh mana sistem bangunan hijau diterapkan di dalamnya. Penelitian ini bertujuan untuk mengetahui seberapa jauh sistem bangunan hijau diterapkan di dalamnya. Metode yang digunakan dalam penelitian adalah observasi, wawancara, dan komparasi realita lapangan dengan tolok ukur Greenship Existing Building Version 1.1 dengan waktu penelitian selama 6 bulan. Berdasarkan penelitian yang telah dilakukan dengan metode tersebut didapatkan hasil bahwa Rumah Rempah Karya mendapatkan peringkat silver dengan poin yang diperoleh sebanyak 53 poin. Rumah Rempah Karya belum dapat menghasilkan poin dalam kategori konservasi air. Perlu dilakukan upaya-upaya untuk mengkonservasi air agar poin ini mendapat peringkat, sehingga penerapan sistem bangunan hijau dapat lebih terlaksana secara menyeluruh di dalamnya.
\end{abstract}

KATA KUNCI: rumah rempah karya, bangunan hijau, material sisa proyek

\section{PENDAHULUAN}

\section{Bangunan Hijau}

Bangunan hijau (dikenal juga sebagai konstruksi hijau atau bangunan berkelanjutan) mengarah pada struktur dan pemakaian proses yang bertanggung jawab terhadap lingkungan dan hemat sumber daya sepanjang siklus hidup bangunan tersebut, mulai dari pemilihan tempat sampai desain, konstruksi, operasi, perawatan, renovasi, dan peruntukan. Praktik ini memperluas dan melengkapi desain bangunan klasik dalam hal ekonomi, utilitas, durabilitas, dan kenyamanan (Environmental Protection Agency, 2016).

\section{Sustainable Architecture (Arsitektur Berkelanjutan)} Arsitektur berkelanjutan merupakan suatu bentuk arsitektur yang memenuhi kebutuhan saat ini, tanpa membahayakan kemampuan dan kebutuhan generasi mendatang (Syamsiyah, Utami, \& Dharoko, 2015).
Sustainable Architecture memiliki 3 komponen utama yaitu keberlanjutan ekonomi, keberlanjutan lingkungan, dan keberlanjutan sosial. Pencapaian arsitektur berkelanjutan dapat dilakukan dengan cara melakukan Natural Landscaping, Site Preservation (dapat dilakukan dengan menggunakan Botanical Garden, Biology Pond, Green Roof, Native Plantings), Visual Amenity, Economic and Social Well-being, Daylighting and Natural Ventilation, Water Management, Reduce, Reuse, Recycle \& Renewable Material, Embodied Energy and Energy Efficiency

\section{GBCl (Green Building Council Indonesia)}

Lembaga Konsil Bangunan Hijau Indonesia atau Green Building Council Indonesia (GBC Indonesia) adalah lembaga mandiri (non-government) yang berkomitmen penuh terhadap pendidikan masyarakat dalam mengaplikasikan praktik-praktik terbaik lingkungan dan memfasilitasi transformasi industri bangunan global yang berkelanjutan. 


\section{Rumah Rempah Karya}

Bangunan ini terwujud karena ada kebutuhan akan gudang baru untuk menyimpan sisa-sisa pembangunan dan produksi kayu yang dikumpulkan oleh Paulus Mintarga, sang pemilik. Terdapat serpihan kayu dari sisa produksi mebel kayu atau sisa pembangunan dan potongan rangka besi yang semuanya membutuhkan ruang penyimpanan (Gambar 1).

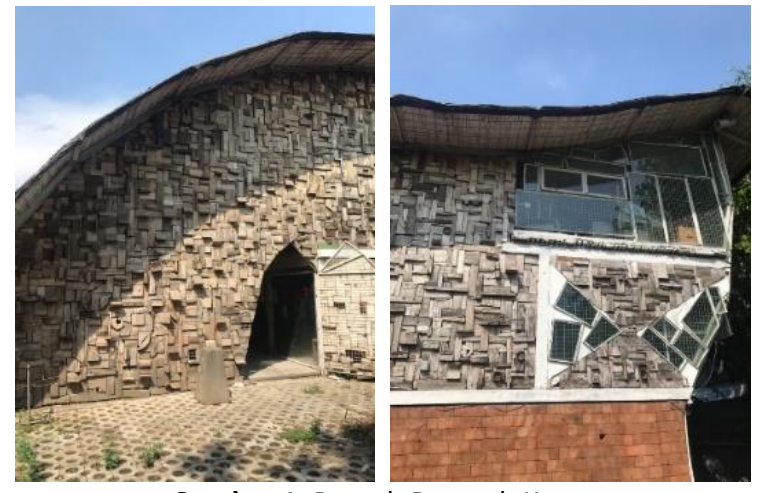

Gambar 1. Rumah Rempah Karya

(sumber: dokumentasi penulis, 2019)

Ide kreatif kemudian berkembang, menjadikan material-material ini tersusun menjadi sebuah bangunan yang mampu mewadahi berbagai macam kegiatan. Berawal dari membutuhkan ruang, kemudian berubah menjadi membentuk ruang.

Secara garis besar, Rempah Rumah Karya ini terdiri dari lima massa. Satu bangunan utama dengan atap kurva, satu bangunan beratap ijuk pelana sebagai area workshop, bangunan gudang di belakang, satu bangunan dua lantai untuk penginapan karyawan, dan satu massa dari rangka besi berbentuk payung yang menjadi tempat pot tanaman dan menaungi area komunal. Suatu pengalaman ruang yang kaya, karena tidak hanya tekstur secara visual tetapi tekstur melalui rabaan, dan aroma kayu.

\section{METODE PENELITIAN}

Penelitian ini menggunakan metode deskriptif kualitatif, yaitu metode penelitian yang memanfaatkan data kualitatif dan dijabarkan secara deskriptif dan kerap digunakan untuk menganalisis kejadian, fenomena, atau keadaan secara sosial. Deskriptif kualitatif diterapkan pada pendeskripsian subyek penelitian, dengan menarasikan keadaan dan sistem yang ada disana. Hal ini juga diterapkan pada pemberian rating tools pada bangunan.

Selain itu, digunakan pula penelitian kuantitatif, yaitu memperoleh data yang berbentuk angka atau data kualitatif yang diangkakan. Penggunaan metode kuantitatif digunakan untuk mengetahui persentase tingkat kenyamanan pada bangunan. Hal ini dilakukakan dengan pengadaan sampling terhadap pengguna bangunan.

Pencarian data dilakukan dengan menggunakan 3 teknik, yaitu observasi, study literatur, dan interview atau wawancara. Seluruh kegiatan yang bersangkutan dengan penelitian ini dilakukan berdasarkan metodemetode yang telah disebutkan dalam waktu 6 bulan.

\section{HASIL PENELITIAN}

Hasil pengamatan dan proses analisis dalam penelitian ini ditampilkan dalam Tabel 1 berikut:

Table 1. Hasil Penelitian

\begin{tabular}{clccc}
\hline No. & \multicolumn{1}{c}{ Kategori } & $\begin{array}{c}\text { Poin } \\
\text { Maksimal } \\
\text { sesuai GBCl }\end{array}$ & $\begin{array}{c}\text { Poin Yang } \\
\text { Diperoleh }\end{array}$ & Selisih \\
\hline 1. & $\begin{array}{l}\text { Tepat Guna } \\
\text { Lahan }\end{array}$ & 16 & 10 & 6 \\
\hline 2. & $\begin{array}{l}\text { Efisiensi Dan } \\
\text { Konservasi } \\
\text { Energi }\end{array}$ & 36 & 15 & 21 \\
\hline 3. & Konservasi air & 20 & 0 & 20 \\
\hline 4. & $\begin{array}{l}\text { Sumber } \\
\text { Material dan } \\
\text { Daur Ulang }\end{array}$ & 12 & 9 & 3 \\
\hline 5. & $\begin{array}{l}\text { Kesehatan dan } \\
\text { Kenyamanan } \\
\text { Ruang }\end{array}$ & 20 & 15 & 5 \\
\hline 6. & $\begin{array}{l}\text { Manajemen } \\
\text { Lingkungan } \\
\text { dan Bangunan }\end{array}$ & 12 & 4 & 8 \\
\hline \multicolumn{1}{c}{ TOTAL } & $\mathbf{1 1 7}$ & $\mathbf{5 3}$ & $\mathbf{6 4}$ \\
\hline
\end{tabular}

\section{PEMBAHASAN}

Dalam penilaian tepat guna lahan, penilaian kriteria prasyarat terpenuhi dengan adanya kebijakan manajemen tapak. Untuk penilaian kriteria lain didapatkan 10 poin. Dalam penilaian efisiensi dan konservasi energi kriteria Policy and Energy Management Plan terpenuhi dengan adanya kampanye dalam rangka mendorong penghematan energi. Sedangkan kriteria lain mendapatkan 15 poin. Dalam penilaian konservasi air, Rumah Rempah Karya tidak dapat melakukan penilaian, disebabkan belum ada upaya untuk melakukan konservasi air. Dalam penilaian sumber material dan daur ulang, kriteria Fundamental Refrigerant terpenuhi dengan penggunaan refrigerant non-CFC. Dalam kriteria lain mendapatkan poin sebanyak 9 poin. Dalam penilaian kesehatan dan kenyamanan ruang, kriteria No Smoking Campaign dapat tercapai dengan adanya surat pernyataan dan kampanye larangan merokok. Dalam kriteria lain mendapatkan 15 poin. Dalam penilaian manajemen lingkungan dan bangunan, kriteria Operation \& Maintenance Policy terpenuhi 
dengan adanya rencana operation dan maintenance yang mendukung sarana pencapaian rating-rating Greenship Existing Building. Dalam kriteria lain mendapatkan 4 poin. Jumlah point keseluruhan adalah 53 poin dengan apresiasi silver.

Berdasarkan hasil wawancara yang telah dilakukan dengan pemilik sekaligus pengelola Rumah Rempah Karya ini, penerapan sistem green building rupanya memberikan dampak yang cukup signifikan. Dampak tersebut terkait dengan kenyamanan pengguna saat berada di dalam bangunan dan konsumsi energi listrik yang sedikit. Dalam kenyamanan pengguna, bangunan memang dirasa lebih ideal daripada bangunan perkantoran lain yang cenderung tertutup dan terkesan penat. Sinar matahari dan udara yang alami memberikan feel yang berbeda dan cenderung merelaksasi diri pengguna. Selain itu, keadaan psikologis pengguna bangunan dapat selalu terjaga dari hal-hal seperti strees dan penat. Hal ini dikarenakan kondisi lingkungan yang menyerupai alam ternyata mendorong mood untuk selalu fresh. Dari segi konsumsi energi penerapan sistem green building juga memberikan dampak yang baik. Konsumsi energi listrik menjadi lebih tertekan dengan adanya penggunaan pencahayaan dan penghawaan alami. Selain itu lingkungan juga lebih terasa asri dengan adanya lahan yang diharuskan untuk menjadi ruang terbuka hijau baik privat maupun non-privat. Perkerasan yang diadakan dengan angka maksimal juga memberika peresapan air yang baik pada tanah, sehingga tidak terjadi genangan atau banjir di Rumah Rempah Karya.

\section{KESIMPULAN}

Berdasarkan hasil pengamatan dan penilaian yang telah dilakukan terhadap Bangunan Rumah Rempah Karya dengan tolok ukur Greenship Existing Building Version 1.1, Rumah Rempah Karya mendapatkan 53 poin dengan predikat Silver. Pencapaian yang didapatkan menyimpulkan bahwa Rumah Rempah Karya sudah menerapkan sistem green buiding namun belum maksimal. Perlu adanya pembenahan guna mendapatkan hasil yang maksimal sehingga seluruh kriteria dapat dicapai seluruhnya.

Romendasi yang dapat diberikan kepada Rumah Rempah Karya adalah untuk tetap mempertahankan apa yang telah dicapai dalam rating greenship dengan acuan ukur Greenship Existing Building Version 1.1. Adapun kriteria-kriteria yang belum mampu dipenuhi untuk segera diusahakan agar terpenuhi, terutama dalam hal konservasi air. Dalam perawatan bangunan diharap Rumah Rempah Karya lebih memperhatikan kebersihan bangunan dari debu agar bangunan lebih bersih dan terawat.

\section{DAFTAR PUSTAKA}

Syamsiyah N.R., Utami S.S., Dharoko A. (2015) Rancangan Arsitektur Berkelanjutan Melalui Metode Soundscape, Jurnal FTUMJ ISSN: 24071846, Jakarta

U.S. Environmental Protection Agency (2009). Green Building Basic Information. [online]

http://www.epa.gov/greenbuilding/pubs/about.htm [diakses pada 28 Oktober 2019] 